Received Date : 23-Aug-2015

Accepted Date : 04-Nov-2015

Article type : Original Papers

\title{
Risk of early relapse following switch from injectables to oral agents for multiple sclerosis
}

Tim Spelman ${ }^{1,2}$ (MBBS), Linda $\operatorname{Mekhael}^{3}(\mathrm{PhD})$, Therese Burke ${ }^{3}(\mathrm{PhD})$, Helmut Butzkueven $^{1,2}(\mathrm{PhD})$, Suzanne Hodgkinson $^{4}(\mathrm{PhD})$, Eva Havrdova $^{5}(\mathrm{PhD})$, Dana Horakova ${ }^{5}$ $(\mathrm{PhD})$, Pierre Duquette ${ }^{6}(\mathrm{MD})$, Guillermo Izquierdo ${ }^{7}(\mathrm{PhD})$, Francois Grand'Maison ${ }^{8}(\mathrm{MD})$, Pierre Grammond $^{9}$ (MD), Michael Barnett ${ }^{10}(\mathrm{PhD})$, Jeannette Lechner-Scott ${ }^{11}$ (MD), Raed Alroughani $^{12}(\mathrm{MD})$, Maria Trojano ${ }^{13}(\mathrm{MD})$, Alessandra Lugaresi ${ }^{14}(\mathrm{MD})$, Franco Granella ${ }^{15}$ (MD), Eugenio Pucci ${ }^{16}(\mathrm{PhD}) \&$ Steve Vucic ${ }^{3}(\mathrm{PhD})$ on behalf of the MSBase Study Group

${ }^{1}$ Department of Neurology, Royal Melbourne Hospital, Parkville, Australia

${ }^{2}$ Department of Medicine (RMH), The University of Melbourne, Parkville, Australia

${ }^{3}$ Westmead Hospital, Sydney, Australia

${ }^{4}$ Liverpool Hospital, Sydney, Australia

${ }^{5}$ Charles University, Prague, Czech Republic

${ }^{6}$ Hôpital Notre Dame, Montreal, Canada

${ }^{7}$ Hospital Universitario Virgen Macarena, Sevilla, Spain

${ }^{8}$ Neuro Rive-Sud, Hôpital Charles LeMoyne, Quebec, Canada

${ }^{9}$ Center de réadaptation déficience physique Chaudière-Appalache, Levis, Canada

${ }^{10}$ Brain and Mind Research Institute, Sydney, Australia

11. John Hunter Hospital, Newcastle, Australia

${ }^{12}$ Amiri Hospital, Kuwait City, Kuwait

${ }^{13}$ Department of Basic Medical Sciences, Neuroscience and Sense Organs, University of Bari, Bari, Italy

${ }^{14}$ MS Center, Department of Neuroscience, Imaging and Clinical Sciences, University ' $G$. d'Annunzio', Chieti, Italy

This is the author manuscript accepted for publication and has undergone full peer review but has not been through the copyediting, typesetting, pagination and proofreading process, which may lead to differences between this version and the Version of Record. Please cite this article as doi: 10.1111/ene.12929

This article is protected by copyright. All rights reserved 
${ }^{15}$ Department of Neurosciences, University of Parma, Parma, Italy

${ }^{16}$ Neurology Unit, ASUR Marche - AV3, Macerata, Italy.

\section{Corresponding author:}

Professor Steve Vucic

Department of Neurology, Westmead Hospital

Cnr Hawkesbury and Darcy Roads,

Westmead, NSW, 2145, Australia

$\mathrm{Ph}:+6198456097$

Email: s.vucic@neura.edu.au ; Steve.vucic@sydney.edu.au

Running title: Early relapse risk post-switch to oral MS treatment

Keywords: treatment switching, multiple sclerosis, fingolimod, dimethyl fumarate, teriflunomide, relapse, progression

\section{Funding: none.}

\section{Author Disclosures:}

Tim Spelman received honoraria for consultancy, funding for travel and compensation for serving on scientific advisory boards from Biogen Idec Inc; speaker honoraria from Novartis. Linda Mekhael did not declare any competing interests.

Therese Burke received compensation for serving on scientific advisory boards and as a consultant for Biogen Idec and Bayer; speaker honoraria from Merck Serono Australia, Genzyme and Biogen Idec and travel support from Biogen Idec Australia and Novartis Australia .

Helmut Butzkueven received compensation for serving on scientific advisory boards and as a consultant for Biogen Idec and Novartis; speaker honoraria from Biogen Idec Australia, Merck Serono Australia, and Novartis Australia; travel support from Biogen Idec Australia and Merck Serono Australia; research support from CASS Foundation (Australia), Merck Serono Australia, the Royal Melbourne Hospital Friends of the Neurosciences Foundation, and the University of Melbourne.

Suzanne Hodgkinson did not declare any competing interests. 
Eva Havrdova received speaker honoraria and consultant fees from Biogen Idec, Merck Serono, Novartis, Genzyme and Teva, as well as support for research activities from Biogen Idec and Merck Serono.

Dana Horakova received speaker honoraria and consultant fees from Biogen Idec, Merck Serono, Novartis, Genzyme and Teva, as well as support for research activities from Biogen Idec and Merck Serono.

Pierre Duquette has received honoraria for organising CME events and has obtained funding to attend meetings from Biogen Idec, EMD Serono, TEVA Neuroscience, Novartis, and Genzyme, has received funding for investigator-initiated trials with Biogen Idec, EMD Serono and Novartis, and has received peer-review funding from CIHR and from the MS Society of Canada.

Guillermo Izquierdo received consulting fees from Bayer Schering, Biogen Idec, Merck Serono, Novartis, Sanofi, and Teva.

Francois Grand'Maison received an honorarium for organizing a CME event for Biogen Idec in 2013 and received consultation fees from Biogen Idec as well as from Novartis and Genzyme in 2013 and 2014.

Pierre Grammond is a Novartis, Teva-neuroscience, Biogen Idec advisory board member, consultant for Merck Serono, received payments for lectures by Merck Serono, TevaNeuroscience and Canadian Multiple sclerosis society, and received grants for travel from Teva-Neuroscience and Novartis.

Michael Barnett has received honoraria for participation in advisory boards and travel sponsorship from Novartis, BioCSL, Genzyme and Biogen Idec

Jeannette Lechner-Scott has accepted travel compensation from Novartis, Biogen and Merck Serono. Her institution receives the honoraria for talks and advisory board commitment and also clinic support from Bayer Health Care, Biogen Idec, CSL, Genzyme Sanofi, Merck Serono and Novartis.

Raed Alroughani received honororia from Biologix, Bayer, Merck Sorono, GSK and Novartis, and served on advisory board for Biologix, Novartis and Merck Sorono Maria Trojano received honoraria for consultancy and/or speaking from Biogen Idec, Genzyme-Sanofi, Merck Serono, Novartis, and Roche; research grants from Biogen Idec, Merck Serono, Novartis, and Teva.

Alessandra Lugaresi is a Bayer Schering, Biogen Idec, Genzyme, Merck Serono Advisory Board Member. She received travel grants and honoraria from Bayer Schering, Biogen Idec, Merck Serono, Novartis, Sanofi and Teva, research grants from Bayer Schering, Biogen Idec, 
Merck Serono, Novartis, Sanofi and Teva, travel and research grants from the Associazione Italiana Sclerosi Multipla.

Franco Granella has served on scientific advisory boards for Biogen Idec, Novartis and Sanofi Aventis and has received funding for travel and speaker honoraria from Biogen Idec, Merck Serono, and Almirall.

Eugenio Pucci served on scientific advisory boards for Genzyme, Novartis and Biogen-Idec; he has received honoraria and travel grants from Sanofi Aventis, Novartis, Biogen Idec, Merck Serono, Genzyme and Teva; he has received travel grants from Associazione Marchigiana Sclerosi Multipla e altre malattie neurologiche.

Steve Vucic did not declare any competing interests.

\section{ABSTRACT}

Background: Early relapse outcomes in long-term stable patients switching from IFN $\beta / G A$ to oral therapy are unknown.

Objective: The objective of this study was to compare early relapse and progression in MS patients switching to oral therapy following a period of stable disease on interferon-beta or glatiramer acetate (IFN $\beta / \mathrm{GA})$, relative to a propensity-matched comparator of patients remaining on IFN $\beta / G A$.

Methods: The MSBase cohort study is a global, longitudinal registry for Multiple Sclerosis. Time to first 6-month relapse in previously stable MS patients switching from platform injectables ("switchers") to oral agents were compared with propensity matched patients remaining on IFN $\beta /$ GA ("stayers") using a Cox Marginal Model.

Results: Three-hundred and ninety-six switchers were successfully matched to 396 stayers on a 1:1 basis. There was no difference in the proportion of patients recording at least 1 relapse in the first $1-6$ months by treatment arm ( $7.3 \%$ of switchers; $6.6 \%$ stayers, $p=0.675)$. The mean Annualised Relapse Rate $(\mathrm{p}=0.493)$ and the rate of first 6-month relapse by treatment arm (HR 1.22, 95\% CI 0.70, 2.11) were also comparable. There was no difference in the rate of disability progression by treatment arm (HR 1.43, 95\% CI 0.63, 3.26).

Conclusion: This is the first study to compare early relapse switch probability in the period immediately following switch to oral treatment in a population previously stable on injectable therapy. There was no evidence of disease reactivation within the first 6 months of switching to oral thearpy.

\section{INTRODUCTION:}

Switching disease-modifying treatment in multiple sclerosis is common, often triggered by breakthrough disease. ${ }^{1}$ Where disease course is stabilised on platform injectables (IFN $\left.\beta / G A\right)$, 
poor tolerability $^{8-13}$ or the ease of administration offered by the increasing range of oral agents may further motivate patients and/or clinicians to consider a treatment switch. Recent concerns around disease reactivation in patients switching to fingolimod ${ }^{2-7}$ have highlighted the paucity of data on clinical outcomes shortly after switching to oral agents, particularly in previously stable patients seeking to switch for reasons other than breakthrough disease.

In patients with satisfactory disease control on injectables, unacceptable tolerability may form the primary trigger for considering treatment switch. ${ }^{14}$ Increasing availability of oral agents for MS has expanded treatment options. Oral agents including fingolimod, dimethyl fumarate(DMF) and teriflunomide have been reported to reduce MS relapse rates by between $32 \%$ to $55 \%$ relative to placebo in clinical trials. ${ }^{15-20}$ A 12 -month double-blind randomised trail observed a $48 \%$ decrease in relapse frequency on fingolimod relative to IFN $\beta-1 \mathrm{a}-\mathrm{IM},{ }^{19}$ whilst a phase 3 trial of teriflunomide observed no difference in annualised relapse rate (ARR) relative to a sub-cutaneous IFN $\beta$-1a comparator. ${ }^{21}$ A phase 3 comparison of DMF with glatiramer acetate observed a non-significant reduction in annualised relapse rate with $\mathrm{DMF}^{22}$

Head-to-head comparisons of clinical outcomes in patients switching to oral therapy relative to platform injectables are limited in volume. Modelling of switch data from the one-year TRANSFORMS extension trial estimated patients switching from IFN $\beta$-1a-IM to fingolimod on average doubled their time to first relapse. ${ }^{23}$ Observational studies of fingolimod switching have further observed a significant reductions in ARR relative to other injectable agents, including an analysis by this study group which observed fingolimod switches associated with both a lower ARR and a lower rate of confirmed disability progression when compared against switching to IFN $\beta / \mathrm{GA} .^{23,24}$

The current evidence base for clinical outcomes in a treatment switch context is largely limited to patients with active disease. Early relapse outcomes in stable patients switching from IFN $\beta / G A$ to oral therapy are unknown. The objective of this study was to compare early ARR, time to first relapse and disability progression in MS patients switching to oral therapy following a period of stable disease on IFN $\beta / G A$, relative to a propensity-matched comparator of stable patients remaining on pre-baseline IFN $\beta / G A$. This method has been successfully employed previously to derive product comparisons of efficacy outcomes using MSBase registry data. ${ }^{25-26}$ 


\section{Materials \& Methods}

\section{MSBase Registry}

All patients contributing to this study were sourced from the international MSBase Registry, a global, longitudinal, observational registry for Multiple Sclerosis. Established in 2004, the registry prospectively collects disease-related information from consenting patients attending MS treatment centers using an internet-based, physician-owned and operated system www.msbase.org ${ }^{27}$. Informed consent from all patients according to local laws is required for participation in MSBase and the project holds Human Research Ethics Committee approval or exemption at each contributing center.

\section{Inclusions}

Relapsing Remitting MS (RRMS) patients aged between 18 and 75 years inclusive with a baseline EDSS between 0 and 5.5 who had been stable on IFN $\beta /$ GA for a minimum of 12 months prior to baseline and then either switched to an oral agent or remained on IFN $\beta / G A$ for a minimum of 6 months post baseline were included in this analysis. Stable disease was defined as an absence of clinical relapse events, no gadolinium -enhancing $(\mathrm{Gd}+)$ lesions or an increase in the number of T2 lesions on cerebral MRI and no change in EDSS score whilst on injectable DMD treatment within the 12 months pre-baseline. All cases satisfied the Poser criteria for definite MS or the McDonald criteria for MS. ${ }^{28-30}$

\section{Outcomes \& Definitions}

The primary outcome was the occurrence of a relapse event within 1 to 6 months of baseline. Baseline for the switch group was the date of initiation of an oral agent. The baseline date for patients who remained on IFN $\beta /$ GA (the "stayers") was the date of the first observed EDSS visit from $1^{\text {st }}$ January 2010 onwards in the presence of 12 months of stable disease as defined above. A relapse was defined as occurrence of new symptoms or exacerbation of existing symptoms persisting for at least 24 hours, in the absence of concurrent illness or fever, and occurring at least 30 days after a previous attack, also previously applied in an MSBase relapse phenotype analysis. ${ }^{31}$ Disability progression was analysed as a secondary variable. A confirmed disability progression event was defined as $\geq 3$-month confirmed increases of $\geq 0.5$ points for patients with a baseline EDSS score $>5.5, \geq 1.0$ point for those with a baseline EDSS score between 1.0 and 5.5, inclusive, and $\geq 1.5$ points for those with a baseline EDSS score of 0 . EDSS scores recorded within 30 days after a relapse onset were excluded from 
analysis. A switch was defined as commencing an oral DMD within a maximum of three months of discontinuing the prior agent. The date filter for the stayers was identified and applied a priori to ensure both switch and stay groups were contemporaneous (the 2010 start date corresponding to that period in the registry where oral DMD initiations began to be recorded with sufficient frequency).

\section{Statistical analyses}

Categorical variables were summarised using frequency and percentage and compared using a chi-square test. Continuous variables were summarised using mean and standard deviation (SD) or median and inter-quartile range as appropriate, and compared using an analysis of variance or Kruskal-Wallis test as appropriate. A Bonferroni adjustment was applied to correct for multiple comparisons. Patients switching to oral therapy were propensity matched to a comparable patient remaining on IFN $\beta / G A$ using the following baseline variables: age, sex, disease duration, EDSS, number of prior DMD commencements, proportion of disease duration on treatment and number of prior DMD starts as a proportion of baseline disease duration. The propensity score was derived using a logistic regression model where switching to oral DMD formed the dependent outcome variable and the various baseline factors were incorporated into the model as explanatory covariates. Patients from each treatment arm were 1:1 matched according to similarity of propensity score using a 5-to-1 digit matching algorithm. ${ }^{32}$ Given the larger number of IFN $\beta /$ GA stayers available, many-to-one matching (2:1, 3:1 and 4:1) were also attempted. Matching success was assessed through the analysis of paired tests and standardized differences. A Wilcoxon signed-rank test and a McNemar Chi test were used to compare the post-matching balance of continuous and categorical baseline characteristics respectively between matched groups. Imbalance was defined as an absolute standardized difference equal to or greater than $0.20 .^{33}$

Analyses of time to first relapse on treatment and time to three-month confirmed disability progression were performed using a Cox Marginal Model, clustered for the matched pair. Hazard proportionality was assessed via analysis of scaled Schoenfeld residuals and for all models presented in this report, hazard proportionality was satisfied. Simultaneous censoring of the matched pair, censoring each member of the pair at the earliest censor point for each outcome analysed, was used to limit the influence of informative censoring secondary to systematic differences in follow-up duration by treatment arm on event ascertainment. 
Rosenbaum sensitivity analyses across all outcomes were conducted to test the sensitivity of our propensity-matched models to unobserved heterogeneity secondary to baseline characteristics that were either not collected or incompletely observed. ${ }^{34}$ All analyses were undertaken using Stata version 13 (StataCorp, College Station, Texas).

\section{RESULTS}

\section{Patient characteristics}

As of the $28^{\text {th }}$ of January 2015, 401 "switch" patients and 3418 “stay" patients were eligible for propensity matching. Prior to matching, patients that switched to oral medications were older, had a longer disease duration, a greater number of prior DMD therapy commencements and a higher number of prior DMD initiaitons as a proportion of disease duration (Table 1). There was no difference in sex, baseline EDSS and the proportion of disease duration on treatment. There were no differences in the matched sample in any of these characteristics (Table 2). One-to-one matching was preferred for the primary analysis over any of the manyto-one matches secondary to the poorer quality of the secondary, tertiary and quarternary matches. Of the matched switchers, 282 (71.2\%) switched to fingolimod, 64 (16.2\%) to DMF and the remaining $50(12.6 \%)$ to teriflunomide. Median (IQR) time to switching postIFN $\beta / G A$ cessation was 14 days $(0,39)$. Within the matched "stayers", 158 (39.9\%) remained on IFN $\beta$-1a-SC, 122 (30.8\%) glatiramer acetate, 67 (16.9\%) IFN $\beta$-1a-IM with the remaining $49(12.4 \%)$ on IFN $\beta-1 b$. Fingolimod switchers were younger at baseline relative to both $\operatorname{DMF}(\mathrm{p}($ rank-sum $)=0.010)$ and teriflunomide $(\mathrm{p}($ rank-sum $)=0.021)$ had a higher baseline EDSS realtive to both DMF $(\mathrm{p}($ rank-sum $)=0.002)$ and teriflunomide $(\mathrm{p}($ rank-sum $)<0.001)$. There was no difference in gender, disease duration and prior DMD exposure by oral switch product. Within the switchers, the reason for discontinuation of the pre-switch DMD was recorded for only $217(54.8 \%)$ patients. Amongst these patients, the most frequently reported reasons for discontinuation were "lack of tolerance" ( $n=68$ or $31.3 \%$ of the 217 switchers recording a discontinuation reason) and "convenience" ( $\mathrm{n}=64,29.5 \%)$.

\section{Relapse}

Fifty-five $(6.9 \%)$ of the 792 matched patients recorded a relapse event in the 6 months following baseline. There was no difference in the proportion of patients recording at least 1 relapse in the first 1-6 months post-baseline by treatment arm (7.3\% of switchers compared with $6.6 \%$ stayers, $\mathrm{p}($ McNemar $)=0.675)$. In addition, there was no difference in the mean (SD) annualised relapse rate (ARR) within the first 6 months of baseline between the switch 
group $(0.2$ [0.7]) and the stayers $(0.2$ [0.6], $\mathrm{p}($ signed-rank $)=0.4931)$. There was no difference in the rate of first 6-month relapse by matched study arm (HR 1.22, 95\% CI 0.70, 2.11) (Figure 1).

\section{Disability progression}

Within the first 6 months after switching to oral therapy there were $9(2.3 \%)$ confirmed progression events compared with $4(1.0 \%)$ in the stayers $(\mathrm{p}($ McNemar $)=0.269)$. In addition, there were no differences in the rate of first disability progression events between switchers and stayers (HR 1.43, 95\% CI 0.63, 3.26, reference=stayers).

\section{Sub-group analysis}

Amongst switchers, there was no difference in the rate of first 6-month relapse between the three oral agents (DMF adjusted HR: $1.38,95 \%$ CI 0.56, 3.42; teriflunomide: aHR 0.58, $95 \%$ CI 0.13, 2.39; reference $=$ fingolimod), when adjusted for baseline differences in age and EDSS. Amongst switchers the length of washout period was not associated with either early relapse (HR 0.83,95\% CI 0.62, 1.11; reference= less than 2 months) or significant disability progression (HR 1.33, 95\% CI 0.68, 2.62; reference=less than 2 months).

\section{Sensitivity analyses}

Reapplying these models across full patient post-baseline on-treatment follow-up, there was no difference in time to any first relapse event between switchers and stayers (HR 0.87; 95\% CI $0.63,1.21$, reference=stayers) (Figure 2). Similarly there was no difference in disability progression on oral therapy when compared with the stayer group (HR 1.48, 95\% CI 0.79, 2.75 , reference=stayers). Furthermore there was no difference in post-baseline on-treatment EDSS change between the switch group (mean (SD): 0.25 (1.21)) and stay group (mean (SD): $0.40(1.06), \mathrm{p}($ signed-rank $)=0.1799)$. Mean $(\mathrm{SD})$ post-baseline on-treatment follow-up was 2.1 (1.8) years. There was no difference in the rate of any first progression event between any of the three oral agents.

\section{Unmeasured confounding}

Rosenbaum sensitivity analyses of our propensity-matched relapse and progression models estimated that an unobserved confounder would need to produce a minimum 1.89 and 2.07 fold increase in the rate of relapse and confirmed disability progression respectively in order to reject the inference of a treatment effect in favour of selection effects. These represent 
improbably large differences in the context of the observed point estimates and associated confidence intervals. This suggests that the effects of unmeasured confounding on the observed associations between treatment arm and both relapse and progression outcomes were not large enough to significantly change the inferences made.

\section{DISCUSSION}

Poor tolerability of IFN $\beta /$ GA in patients demonstrating otherwise good control of disease on treatment is an increasingly common challenge for both patients and clinicians. Sub-optimal adherence secondary to administration issues or side effect profiles of platform injectables, increases the probability of breakthrough disease, which in turn risks undoing the good work of prior therapy. The broader range of oral therapies now available has considerably expanded the options for sequencing treatments in response to breakthrough disease and tolerability issues. This is the first study to examine the real world risk of early relapse in stabilised MS patients switching to oral therapy against a propensity matched comparator arm of patients with similar duration of stable disease who remain on IFN $\beta / G A$.

Treatment benefits observed in controlled trial settings can only be realised in clinical practice if patients are fully adherent with treatment regime. Administration convenience and patient preference for oral formulations, particularly in the setting of injection anxiety and previous experience with injection site reactions, may improve treatment adherence and thus maximise the efficacy available from oral agents. Such gains need to be balanced with potential risk of disease reactivation in the months shortly following treatment switch. ${ }^{2-7}$ The risk of early relapse following oral switch may be weighted higher by patients in our study population of long-term disease stable switchers relative to patients switching secondary to breakthrough disease. Our results suggest that early relapse in previously stable patients following a switch to oral agents was rare (only $7.3 \%$ of 396 switchers recorded a relapse within 1-6 months post switch). Further there was no difference in either the proportion of patients recording an early relapse event, the ARR or time to first relapse in switchers compared to stable patients who remained on baseline IFN $\beta /$ GA therapy.

Disability progression, as measured by the EDSS, was also infrequent and no difference was observed between switchers and stayers within the first six months post-baseline. Whilst the present study did not establish significant differences in short-term disability progression, this 
analysis was only exploratory since progression, unlike relapse rates, is observed and confirmed over several time points. It is unlikely that six months would be sufficiently long enough to characterise confirmed disability progression with appropriate power. This is consistent with the experience of clinical trials using disability progression as a study endpoint. $^{15,20}$

On sensitivity analysis, stable patients switching to oral treatment demonstrated no difference in either rate of first relapse and first confirmed disability progression over long-term followup relative to the "stayers". The present findings suggest that disease remains quiescent over both the immediate post-switching period (1-6 months) and longer term treatment horizon, at least in this population of previously stable patients. In any event, whilst no increase in event risk was observed in our study, a potential risk of increased disease activity needs to be considered when transitioning a stable RRMS patient from an injectable to oral treatment. In addition, the side-effect profile of oral agents including, but not limited to, bradycardia, gastrointestinal symptoms, flushing, hair-thinning, ${ }^{10,17,20,35}$ needs to be considered, particularly in a population of long-term stable patients considering regimen change. Rarer, severe complications may include the risk of progressive multifocal leukoencephalopathy, infectious or immunosuppressive complications, pregnancy associated sequelae and potential hepatotoxicity also need to be considered when risk-stratifying a previously stable patient for a potential treatment switch. ${ }^{19,20,36}$ Whatever the treatment decision, close monitoring of patients switching to oral agents is suggested given long-term safety profiles are less wellestablished relative to the platform injectables.

A limitation of this study stems from uncontrolled confounding of prognostic factors not included in the propensity match. Confounders that were either not collected or incompletely observed in the registry, such as cerebral and spinal cord MRI disease burden, were not formally adjusted. However, unobserved confounding in this case is unlikely to significantly influence the finding in the present study as indicated by the Rosenbaum sensitivity analysis. Another potential limitation of this study is that clinician-documented reasons for discontinuation were not available for all switches and thus were insufficiently powered to analyse. However of the discontinuation reason data that was available, lack of tolerance and convenience accounted for the majority of documented triggers for discontinuation in these previously stable patients. Whilst such data was available for only just over half the matched switchers $(55 \%)$, it may be reasonable to infer that tolerance and convenience would remain 
key drivers of treatment cessation across the full switcher sample. The relative magnitude of any tolerance or, in particular, convenience gains in switching to a specific oral DMD product needs to be balanced against the risk of adverse event and, depending on the regulatory setting, the expense of switching. A further limitation of this study is the lack of patient reported outcome data which may provide important insights into a patient's real-world experience following switch to oral therapy, particularly in light of the tolerance and convenience discontinuation triggers observed. Such an analysis would constitute an important future expansion of the current study.

The present study argues against the occurrence of rebound disease within the first 6 months of switching to oral thearpy in patients that were stable or injectable or infusable treatments. Switching to an oral agent, in the setting of stable disease, needs careful consideration of the longer-term relapse risk (>6 months). Further studies assessing the factors underlying the increase in longer-term disease activity need to be undertaken in order to develop more appropriate managment algorithms.

\section{Author contributions:}

T Spelman conceptualized and designed the study, conducted the statistical analysis, interpreted the analysis and drafted and revised the paper

L Mehkael interpreted the analysis and revised the paper

T Burke interpreted the analysis and revised the paper

H Butzkueven interpreted the analysis and revised the paper

S Hodgkinson interpreted the analysis and revised the paper

E Havrdova interpreted the analysis and revised the paper

D Horakova interpreted the analysis and revised the paper

P Duquette interpreted the analysis and revised the paper

F Grand-Maison interpreted the analysis and revised the paper

G Izquierdo interpreted the analysis and revised the paper

P Grammond interpreted the analysis and revised the paper

M Barnett interpreted the analysis and revised the paper

J Lechner-Scott interpreted the analysis and revised the paper

R Alroughani interpreted the analysis and revised the paper

M Trojano interpreted the analysis and revised the paper

A Lugaresi interpreted the analysis and revised the paper 
F Granella interpreted the analysis and revised the paper

E Pucci interpreted the analysis and revised the paper

S Vucic conceptualized and designed the study, interpreted the analysis and drafted and revised the paper

\section{REFERENCES}

1. Bonafede, M. M., Johnson, B. H., Wenten, et al. Treatment patterns in disease-modifying therapy for patients with multiple sclerosis in the United States. Clin Ther 2013;35(10):1501-1512

2. Castrop, F., Kowarik, M.C., Albrecht, H., et al. Severe multiple sclerosis relapse under fingolimod therapy: incident or coincidence? Neurology 2012;78:928-930

3. Centonze, D., Rossi, S., Rinaldi, F., et al. Severe relapses under fingolimod treatment prescribed after natalizumab. Neurology 2012;79:2004-2005

4. Vellinga, M.M., Castelijns, J.A., Barkhof, F., et al. Postwithdrawal rebound increase in T2 lesional activity in natalizumab-treated MS patients. Neurology 2008;70:1150-1151

5. Visser, F., Wattjes, M.P., Pouwels, P.J., et al. Tumefactive multiple sclerosis lesions under fingolimod treatment. Neurology 2012;79:2000-2003

6. Cohen, M., Maillart, E., Tourbah, A., et al; Club Francophone de la Sclérose en Plaques Investigators. Switching from natalizumab to fingolimod in multiple sclerosis: a French prospective study. JAMA Neurol. 2014;71(4):436-441

7. Comi, G., Gold, R., Dahlke, F., et al. Relapses in patients treated with fingolimod after previous exposure to natalizumab. Mult Scler;21(6):786-790.

8. Tremlett, H.L. \& Oger, J. Interrupted therapy: stopping and switching of the betainterferons prescribed for MS. Neurology 2003;61:551-554

9. Singer, B., Lucas, S., Kresa-Reahl, K., et al. Optimizing adherence to multiple sclerosis therapies. Int J MS Care 2008;10(Suppl):113

10. Mohr, D.C., Boudewyn, A.C., Likosky, W., et al. Injectable medication for the treatment of multiple sclerosis: the influence of selfefficacy expectations and injection anxiety on adherence and ability to self-inject. Ann Behav Med 2001;23:125-132 
11. Brandes, D.W., Callender, T., Lathi, E., et al. A review of disease-modifying therapies for MS: maximizing adherence and minimizing adverse events. Curr Med Res Opin 2009;25(1):77-92.

12. Treadaway, K., Cutter, G., Salter, A., et al. Factors that influence adherence with diseasemodifying therapy in MS. J Neurol 2009;256(4):568-576

13. Lugaresi, A., Florio, C., Brescia-Morra, V., et al. Patient adherence to and tolerability of self administered interferon beta-1a using an electronic autoinjection device: a multicentre, open-label, phase IV study. BMC Neurol. 2012;12:7

14. Stüve, O., \& Centonze, D. Treatment Decisions for Patients With Active Multiple Sclerosis. JAMA Neurol 2015;1-2.

15. Kappos, L., Radue, E.W., O’Connor, P., et al. A placebo-controlled trial of oral fingolimod in relapsing multiple sclerosis. N Engl J Med 2010;362:387-401.

16. Gold, R., Kappos, L., Arnold, D.L., et al. Placebo-controlled phase 3 study of oral BG-12 for relapsing multiple sclerosis. N Engl J Med 2012;367:1098-1107.

17. Fox, R.J., Miller, D.H., Phillips, J.T., et al. Placebo-controlled phase 3 study of oral BG12 or glatiramer in multiple sclerosis. N Engl J Med 2012;367:1087-1097.

18. O'Connor, P., Wolinsky, J.S., Confavreux, C., et al. Randomized trial of oral teriflunomide for relapsing multiple sclerosis. N Engl J Med 2011;365:1293-1303

19. Cohen, J.A., Barkhof, F., Comi, G., et al. Oral fingolimod or intramuscular interferon for relapsing multiple sclerosis. N Engl J Med 2010;362:402-415.

20. Kappos, L., Comi, G., Confavreux, C., et al. The efficacy and safety of teriflunomide in patients with relapsing MS: results from TOWER, a phase III, placebo-controlled study. Presented at: Congress of the European Committee for Treatment and Research in Multiple Sclerosis 2012, abstract 153. Mult Scler 2012; 18 (S4):50-51.

21. Vermersch, P., Czlonkowska, A., Grimaldi, L. M., et al. Teriflunomide versus subcutaneous interferon beta-1a in patients with relapsing multiple sclerosis: a randomised, controlled phase 3 trial. Mult Scler 2013;20(6):705.. 
22. Meng, X., Cutter, G., Chin, P., Hashmonay, R., et al. Effect of Switching from Intramuscular Interferon b-1a to Fingolimod on Time to Relapse in Patients with Relapsing-Remitting Multiple Sclerosis Enrolled in a 1-Year Extension of TRANSFORMS (P07.107). Neurology 2013;80(Meeting Abstracts 1):P07-107.

23. Bergvall, N., Makin, C., Lahoz, R., et al. Relapse rates in patients with multiple sclerosis switching from interferon to fingolimod or glatiramer acetate: a US claims database study. PLoS One 2014;9(2):e88472.

24. He, A., Spelman, T., Jokubaitis, V., et al; MSBase Study Group. Comparison of switch to fingolimod or interferon beta/glatiramer acetate in active multiple sclerosis. JAMA Neurol 2015;72(4):405..

25. Kalincik, T., Horakova, D., Spelman, T., et al. Switch to natalizumab versus fingolimod in active relapsing-remitting multiple sclerosis. Ann Neurol 2015;77:425-435

26. Spelman, T., Kalincik, T ; Zhang, A et al. Comparative efficacy of switching to natalizumab in active relapsing multiple sclerosis. Ann Clin Transl Neurol 2015;2(4):373-387..

27. Butzkueven, H., Chapman, J., Cristiano, E., et al. MSBase: an international, online registry and platform for collaborative outcomes research in multiple sclerosis. Mult Scler 2006;12:769-774.

28. Poser, C.M., Paty, D.W., Scheinberg, L., et al. New diagnostic criteria for multiple sclerosis: guidelines for research protocols. Ann Neurol 1983;13:227-31.

29. McDonald, W.I., Compston, A., Edan, G., et al. Recommended diagnostic criteria for multiple sclerosis: guidelines from the International Panel on the diagnosis of multiple sclerosis. Ann Neurol 2001;50:121-7.

30. Polman, C. H., Reingold, S. C., Banwell, B., et al. Diagnostic criteria for multiple sclerosis: 2010 revisions to the McDonald criteria. Ann Neurol 2011;69(2):292-302.

31. Kalincik, T., Buzzard, K., Jokubaitis, V., et al. Risk of relapse phenotype recurrence in multiple sclerosis. Mult Scler 2014;20(11):1511. 
32. Parsons, L.S. Reducing bias in a propensity score matched-pair sample using greedy matching techniques. Proceedings of the Twenty-sixth Annual SAS Users group international conference. 2001;26:214-26.

33. Austin, P.C. Balance diagnostics for comparing the distribution of baseline covariates between treatment groups in propensity-score matched samples. Statist Med 2009;28:3083-3107

34. DiPrete, T.A., Gangl, M. Assessing bias in the estimation of causal effects: Rosenbaum bounds on matching estimators and instrumental variables estimation with imperfect instruments. Sociol Methodol 2004;34(1);271-310.

35. Lugaresi, A., Di Ioia, M., Travaglini, D., et al. Risk-benefit considerations in the treatment of relapsing-remitting multiple sclerosis. Neuropsychiatr Dis Treat 2013;9:893.

36. Cohen, A.B. \& Rieckmann, P. Emerging oral therapies for Multiple Sclerosis. Int J Clin Pract 2007;61(11):1922-1930

Table 1 - Baseline characteristics of unmatched patients

\begin{tabular}{|c|c|c|c|}
\hline Baseline Characteristic & $\begin{array}{l}\text { Switch } \\
(n=401)\end{array}$ & $\begin{array}{c}\text { Stay } \\
(n=3418)\end{array}$ & $P$-value \\
\hline Age, years, median (IQR) & $\begin{array}{c}41.7(35.1, \\
49.8)\end{array}$ & $\begin{array}{c}40.1(32.9 \\
48.1)\end{array}$ & 0.0016 \\
\hline Female sex, $\mathrm{n}(\%)$ & $301(75.1)$ & $2443(71.5)$ & 0.131 \\
\hline $\begin{array}{l}\text { Disease duration, years, } \\
\text { median (IQR) }\end{array}$ & $\begin{array}{l}9.1(5.7 \\
15.2)\end{array}$ & $\begin{array}{c}9.0(4.7, \\
14.6)\end{array}$ & 0.0457 \\
\hline EDSS, median (IQR) & $1.5(1,3)$ & $1.5(1,2.5)$ & 0.3286 \\
\hline Number of prior DMD starts - mean (SD) & $1.7(1.2)$ & $0.5(0.8)$ & $<0.0001$ \\
\hline $\begin{array}{l}\text { Proportion disease duration on treatment - mean } \\
\text { (SD) }\end{array}$ & $0.6(0.3)$ & $0.6(0.3)$ & 0.0884 \\
\hline $\begin{array}{l}\text { Number of prior DMD starts as a proportion of } \\
\text { disease duration - mean (SD) }\end{array}$ & $0.2(0.2)$ & $0.1(0.1)$ & $<0.0001$ \\
\hline
\end{tabular}

Abbreviations: EDSS = Expanded Disability Status Scale; IQR = interquartile range; SD = standard deviation; DMD = Disease-Modifying Drug 
Table 2 - Baseline characteristics of propensity score-matched patients

\begin{tabular}{lccc}
\hline Baseline Characteristic & $\begin{array}{c}\text { Switch } \\
(\mathbf{n = 3 9 6})\end{array}$ & $\begin{array}{c}\text { Stay } \\
(\mathbf{n = 3 9 6})\end{array}$ & $\begin{array}{c}\boldsymbol{P} \text { - } \\
\text { value* }\end{array}$ \\
\hline Age, years, median (IQR) & $41.7(35.0$, & $42.9(35.1$, & \\
\hline Female sex, n (\%) & $49.8)$ & $51.5)$ & 0.2121 \\
\hline Disease duration, years, & $298(75.3)$ & $296(74.8)$ & 0.8676 \\
median (IQR) & $10.7(6.1$, & $11.5(6.3$, & \\
\hline EDSS, median (IQR) & $16.7)$ & $17.4)$ & 0.1531 \\
\hline Number of prior DMD starts - mean (SD) & $2.0(1,3)$ & $2.0(1,2.5)$ & 0.5290 \\
\hline Proportion disease duration on treatment - mean & $1.7(1.1)$ & $1.7(1.2)$ & 0.2710 \\
(SD) & $0.6(0.3)$ & $0.6(0.3)$ & 0.8991 \\
\hline Number of prior DMD starts as a proportion of & & & \\
disease duration - mean (SD) & $0.2(0.2)$ & $0.2(0.2)$ & 0.1622 \\
\hline
\end{tabular}

Abbreviations: EDSS = Expanded Disability Status Scale; IQR = interquartile range; SD = standard deviation; DMD = Disease-Modifying Drug

*All post-matching baseline characteristics had a standardized difference between $-20 \%$ and $+20 \%$.

\section{Figure legends}

Figure 1 - Time to first relapse within 6 months post-baseline

Note: Vertical axis scaled to 0.50 through 1.00

Figure 2 - Sensitivity analysis: Time to any first post-baseline relapse 

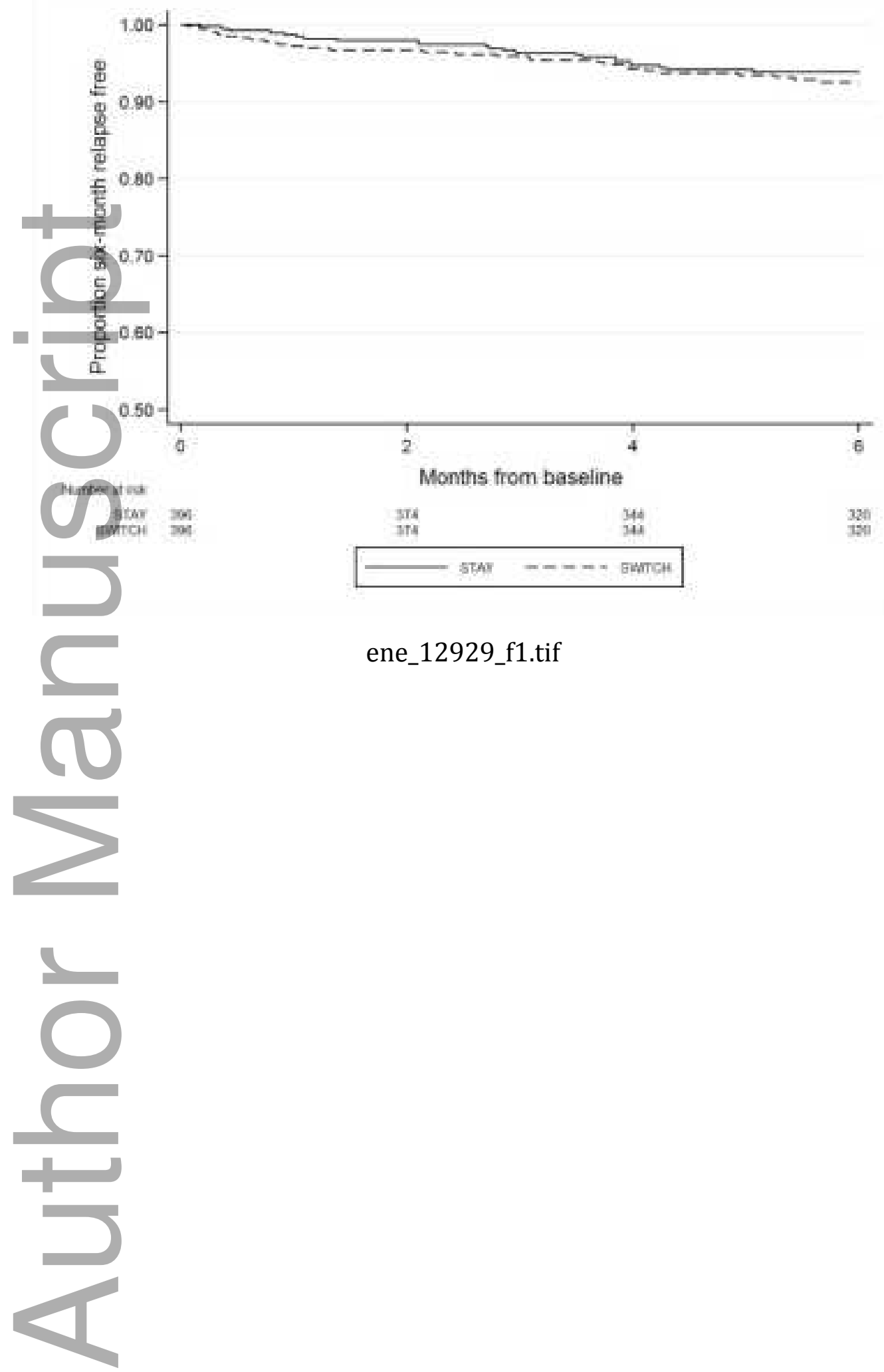

This article is protected by copyright. All rights reserved 

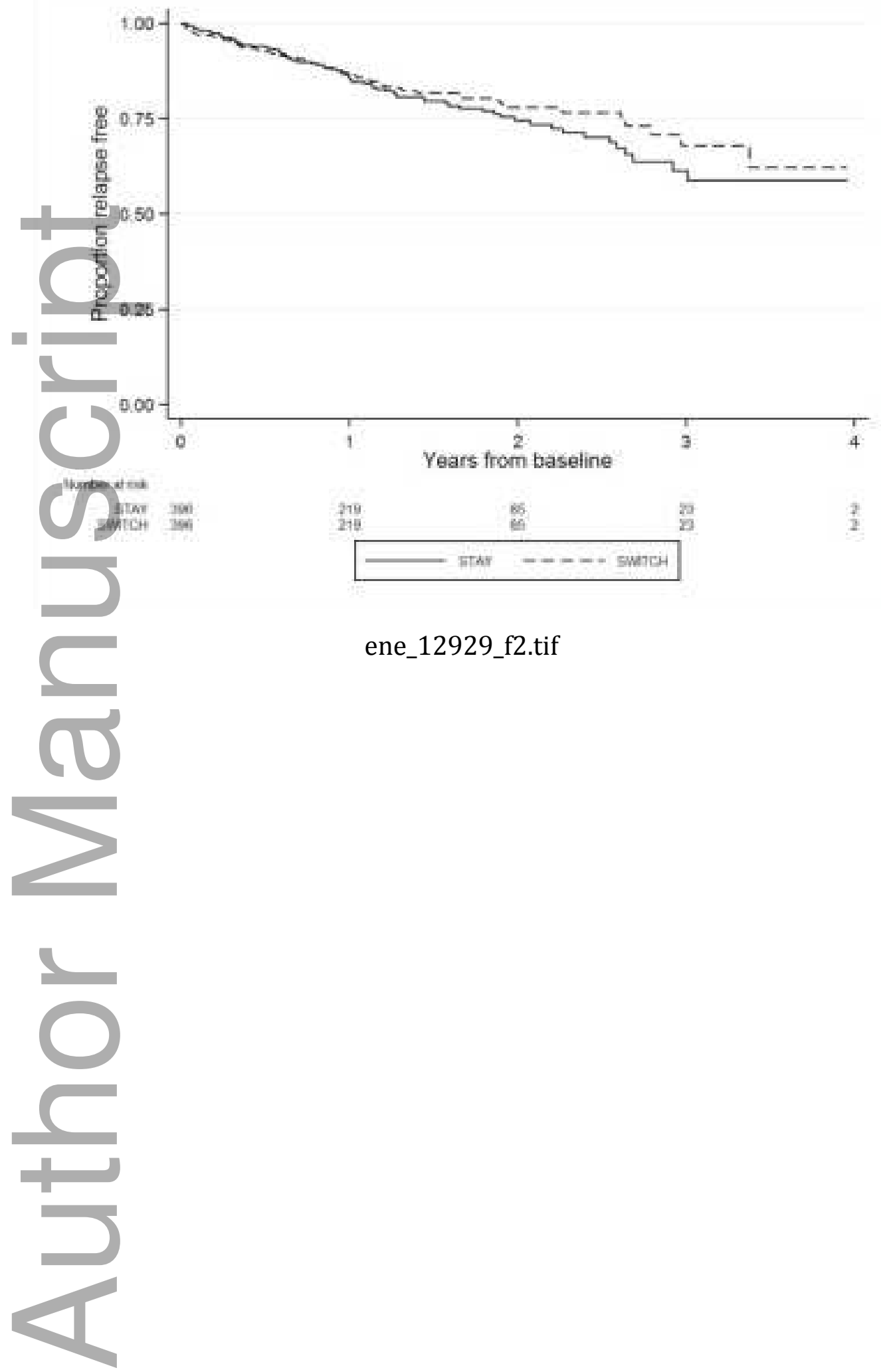


\section{University Library}

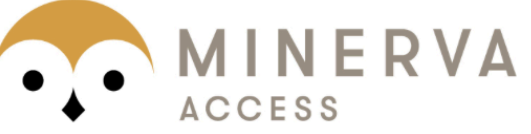

A gateway to Melbourne's research publications

Minerva Access is the Institutional Repository of The University of Melbourne

\section{Author/s:}

Spelman, T;Mekhael, L;Burke, T;Butzkueven, H;Hodgkinson, S;Havrdova, E;Horakova, D;Duquette, P;Izquierdo, G;Grand'Maison, F;Grammond, P;Barnett, M;Lechner-Scott, J;Alroughani, R;Trojano, M;Lugaresi, A;Granella, F;Pucci, E;Vucic, S

Title:

Risk of early relapse following the switch from injectables to oral agents for multiple sclerosis

Date:

2016-04-01

\section{Citation:}

Spelman, T., Mekhael, L., Burke, T., Butzkueven, H., Hodgkinson, S., Havrdova, E., Horakova, D., Duquette, P., Izquierdo, G., Grand'Maison, F., Grammond, P., Barnett, M., Lechner-Scott, J., Alroughani, R., Trojano, M., Lugaresi, A., Granella, F., Pucci, E. \& Vucic, S. (2016). Risk of early relapse following the switch from injectables to oral agents for multiple sclerosis. EUROPEAN JOURNAL OF NEUROLOGY, 23 (4), pp.729-736. https:// doi.org/10.1111/ene.12929.

Persistent Link:

http://hdl.handle.net/11343/290844 